\title{
Successful treatment of non-familial haemophagocytic lymphohistiocytosis with interferon and gammaglobulin
}

\author{
E J Estlin, R D Palmer, K P Windebank, M F Lowry, A D J Pearson
}

\begin{abstract}
Two cases of non-familial haemophagocytic lymphohistiocytosis (HLH) are presented in which treatment with interferon alfa and gammaglobulin was associated with complete clinical remission. In one case, serological evidence of recent Epstein-Barr virus infection was found. Natural killer cell activity was within normal limits in both children, compatible with a secondary form of HLH. The combination of interferon alfa and intravenous gammaglobulin requires further evaluation in the treatment of nonfamilial HLH.
\end{abstract}

(Arch Dis Child 1996;75:432-435)

Keywords: haemophagocytic lymphohistiocytosis, interfornalfa, intravenous gammaglobulin.

Haemophagocytic lymphohistiocytosis (HLH) is a rare disorder characterised by proliferation and activation of morphologically benign histiocytes.' Both familial and secondary (including infection associated) forms of the disease are recognised. ${ }^{2}$ The aetiology of $\mathrm{HLH}$ remains unclear and a defect in the immune modulation of histiocytes by $T$ cells has been suggested. ${ }^{3}$ Familial HLH has a high mortality and treatment is currently based on corticosteroids, etoposide, cyclosporin, and allogenic bone marrow transplantation. ${ }^{4}$ The mortality for secondary (infection associated) $\mathrm{HLH}$ is also high with supportive care alone, and treatment has therefore been directed at the underlying immune activation. However, most cases require non-specific immunomodulation with etoposide, corticosteroids, gammaglobulin and, in resistant cases, allogenic bone marrow transplantation. ${ }^{3}$

We present two cases of non-familial HLH, one associated with Epstein-Barr virus (EBV) infection, and one with an undetermined but presumed infective origin, in which treatment with interferon alfa and intravenous gammaglobulin was associated with complete clinical recovery.

\section{Case reports}

CASE 1

A 20 month old girl presented with a three day history of malaise, fever, and rash. The child, one of monozygotic twins, had been previously well. Her parents were not related and she had received all appropriate vaccinations.

On examination she was feverish with a maximum temperature of $39^{\circ} \mathrm{C}$. A petechial rash over the lower trunk was found. Small cervical and inguinal lymph nodes were palpable. Abdominal examination revealed moderate hepatomegaly and a grossly enlarged spleen extending to the right iliac fossa.

Initial investigations showed her haemoglobin concentration was $62 \mathrm{~g} / \mathrm{l}$, with a white cell count of $1.7 \times 10^{9} / 1\left(0.8 \times 10^{9} / 1\right.$ neutrophils $)$ and a platelet count of $60 \times 10^{9} / 1$. No blast cells were seen on the blood film and a coagulation screen was normal. A bone marrow biopsy specimen showed substantial involvement of marrow with mature histiocytes, many of which contained ingested red cells. Morphologically, the histiocytes appeared nonmalignant.

No evidence of viral infection was found. Paired serological testing revealed no evidence of infection with cytomegalovirus (IgM negative), human herpes virus (HHV)-6 (IgM negative, polymerase chain reaction for $\mathrm{HHV}-6$ DNA negative), EBV (anti-EBV capsid IgG and IgM negative), and herpes simplex virus (no rise in IgG). Similarly repeat stool, throat, and urine culture were negative for cytomegalovirus and herpes simplex virus infection. Plasma alanine aminotransferase 23 U/1 (5-30), bilirubin $16 \mu \mathrm{mol} / 1(<17)$, and alkaline phosphatase $250 \mathrm{U} / 1$ (90-350) were normal. Plasma fibrinogen $0.9 \mathrm{~g} / 1(1.5-4.5)$ and triglycerides 2.24 $\mathrm{mmol} / \mathrm{l}(0.45-1.80)$ were found to be outside the normal range.

Immunoglobulins $\left(\mathrm{IgG}=10.1 \mathrm{~g} / 1, \mathrm{IgG}_{1}=9.7 \mathrm{~g} / \mathrm{l}\right.$, $\mathrm{IgG}_{2}=0.96 \mathrm{~g} / 1, \mathrm{IgG}_{3}=0.82 \mathrm{~g} /, \mathrm{IgG}_{4}=0.8 \mathrm{~g} / \mathrm{lg} \mathrm{I}=$ $1.48 \mathrm{~g} / \mathrm{l}, \mathrm{IgM}=0.55 \mathrm{~g} / 1$ ) and lymphocyte cell numbers (total lymphocytes $=2.31 \times 10^{9} / 1, \quad T$ cells $=1.84 \times 10^{9} /, \quad \mathrm{CD} 4+=1.13 \times 10^{9} / 1, \quad \mathrm{CD} 8+$ $=0.74 \times 10^{9} / 1$, and $\mathrm{B}$ cells $=0.46 \times 10^{9} / 1$ ) were normal in the patient and her twin. Investigation of natural killer cell function is outlined in fig 1 , where the relative cytotoxicity of the patient's peripheral blood mononuclear cells at the time of her presentation, was compared with that of six controls (including her identical twin sibling). Activity against natural killer cell sensitive (K562) and resistant (Raji, FEMX) targets was measured in a four hour ${ }^{51}$ chromium release assay. With adherent cells present, the patient's natural killer cell function against the K562 cell line was found to be low, but within the control range (fig 1A). Moreover, natural killer cell function was not augmented by adherent cell depletion as is normally expected (fig 1B) and was actually reduced. In the case of the natural killer cell resistant Raji and FEMX cell lines, increased cytotoxicity, similar to lymphokine activated killer (LAK) activity, was seen with adherent cells present when compared to con-

Dr Estlin. 

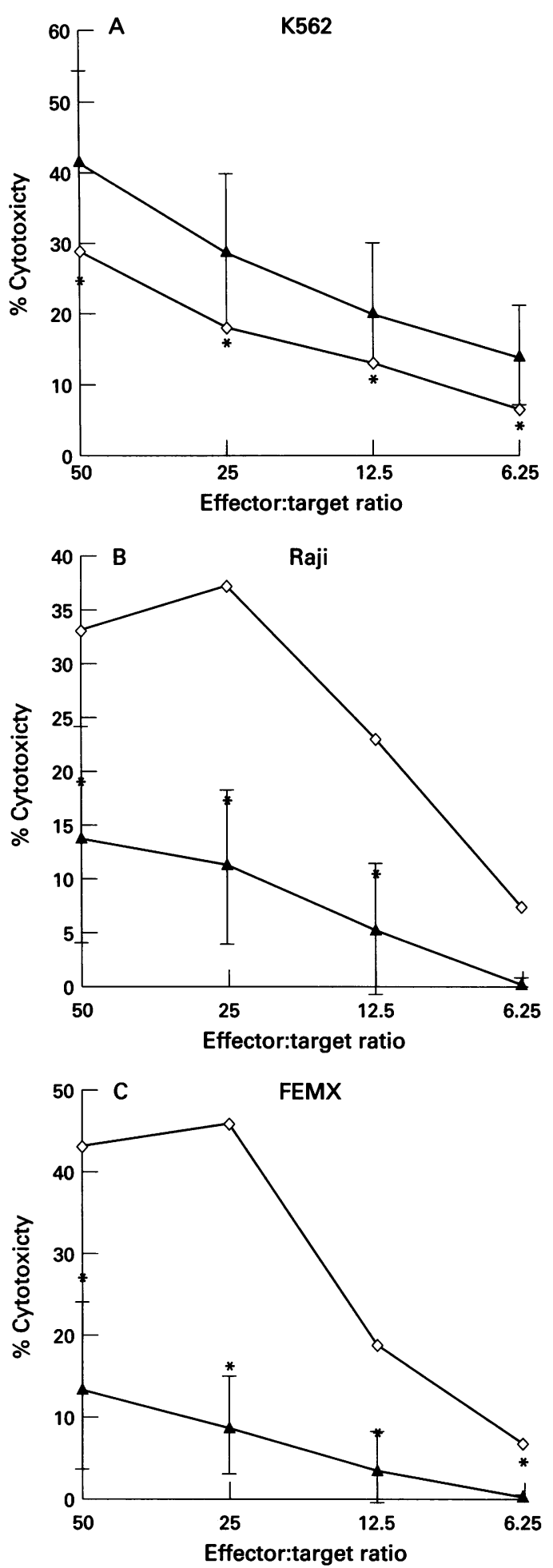

$\neg$ NK/LAK activity with monocytes

* NK/LAK activity without monocytes

$\rightarrow$ NK/LAK activity of 6 controls with SD

Figure 1 Activity of the patients peripheral blood mononuclear cells, compared with that of six controls, as measured in a four hour ${ }^{\text {SI }}$ chromium release assay. $(A)$ Shows activity against the natural killer cell sensitive K562 cell line; $(B)$ and $(C)$ show activity against the natural killer cell resistant Raji and FEMX cell lines respectively (NK = natural killer cell).

trols (fig 1A and C). Removal of adherent cells reduced the cytotoxicity against the Raji and FEMX cell lines to within normal limits.

Treatment was started with high dose acyclovir $(30 \mathrm{mg} / \mathrm{kg} / 24$ hours intravenously for
14 days ) and gammaglobulin $(0.4 \mathrm{~g} / \mathrm{kg} /$ day intravenously for four days, then weekly for one month). However, over the next two weeks her clinical condition deteriorated significantly with further increase in her splenomegaly. She remained febrile and did not respond to antibiotics. Her blood and platelet requirements increased and a repeat bone marrow aspirate and biopsy showed little normal haemopoiesis and almost complete replacement with histiocytes containing ingested cellular material.

Interferon alfa was started (2 million units $/ \mathrm{m}^{2}$ by intramuscular injection, daily for one week, then 3 million units $/ \mathrm{m}^{2}$ three times per week) 14 days after the initiation of treatment with acyclovir and gammaglobulin, and acyclovir was withdrawn. The introduction of interferon alfa resulted in dramatic clinical improvement, with resolution of fever within 72 hours and cessation of transfusion dependence. After two weeks of treatment with interferon and gammaglobulin a bone marrow biopsy specimen showed active, normal haemopoiesis and very few histiocytes.

Intravenous gammaglobulin was continued at monthly intervals for eight months. Treatment with interferon alfa was discontinued after one year, at which time the marrow was normal apart from a few scattered, iron laden macrophages. The child remains well with no detectable splenomegaly and normal peripheral blood counts six years after her initial presentation. Natural killer cell function testing was repeated after five years' remission and was found to be within normal limits with no evidence of LAK activity. Thus far, her identical twin sister remains unaffected.

CASE 2

An 18 month old girl presented with a three day history of fever, anorexia, petechial rash, lethargy, and malaise. Her history included a febrile convulsion two months previously, and she was fully immunised. The parents were non-consanguineous, and her 3 year old sister was well.

Examination revealed she was feverish with a temperature of up to $40^{\circ} \mathrm{C}$, with some petechiae in each groin crease. Additional findings included cervical lymphadenopathy, tonsillar hyperplasia, moderate splenomegaly, and perineal candidiasis. Initial investigations showed thrombocytopenia on a peripheral blood count, with a platelet count of $69 \times 10^{9} / 1$, haemoglobin concentration of $101 \mathrm{~g} / 1$, and white cell count $7.0 \times 10^{9} / 1\left(1.5 \times 10^{9} / 1\right.$ neutrophils; $5.1 \times 10^{9} / 1$ lymphocytes). Examination of a peripheral blood film revealed reactive lymphocytes. Plasma biochemistry showed abnormally raised lactate dehydrogenase $(1600 \mathrm{U} / \mathrm{l})$ and alanine aminotransferase (262 $U / 1)$. The clinical suspicion of EBV infection was confirmed on serological investigation (EBV capsid IgM positive). During the outpatient course EBV IgG titres were observed to rise from 1:40 to 1:160 at two and four weeks after presentation respectively. No evidence of parvovirus, cytomegalovirus, herpes simplex virus, and HHV-6 viral infection was found on paired serological testing. 
Five weeks after the initial presentation with EBV infection, she represented with a four day history of persistent fever, pallor, anorexia, and irritability. On examination she was pale, febrile to $39^{\circ} \mathrm{C}$, with cervical lymphadenopathy and massive hepatosplenomegaly. Laboratory investigations showed a haemoglobin of $56 \mathrm{~g} / \mathrm{l}$, white cell count of $4.1 \times 10^{9} / 1\left(1.5 \times 10^{9} / 1\right.$ neutrophils), and a platelet count of $128 \times 10^{9} / 1$. No blast cells were seen on blood film. Immunoglobulins were normal (IgG=7.3 g/l, $\operatorname{IgA}=0.4 \mathrm{~g} / \mathrm{l}, \operatorname{Ig} M=1.4 \mathrm{~g} / \mathrm{l})$, as was the lactate dehydrogenase (459 U/1) and cerebrospinal fluid examination (no abnormal cells with normal protein and glucose). Triglycerides were raised at $4 \mathrm{mmol} / \mathrm{l}$. High density lipoprotein cholesterols were depressed at $0.4 \mathrm{mmol} / 1$ and low density lipoprotein cholesterols were within normal limits at $2.4 \mathrm{mmol} / 1$ respectively, as was the sodium $(132 \mathrm{mmol} / \mathrm{l})$ and albumin $(29 \mathrm{~g} / \mathrm{l})$. Additionally, clotting times were normal (prothrombin time $=13.5 \mathrm{sec}$; acti-

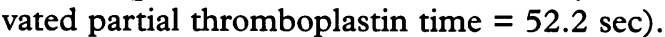

Natural killer cell function, as determined by the mononuclear cell activity against the natural killer cell sensitive myelogenous leukaemia cell line K562 (expressed as the percentage of K562s killed at the effector:target ratio 100:1) was $15.8 \%$ (normal range in children aged 0-12 years being 7.5-27.5\%). Prominent macrophages, some containing phagocytosed leukocytes and erythrocytes were seen on bone marrow aspirate. Bone marrow trephine showed massive infiltration by non malignant histiocytes, many containing ingested nucleated cells, erythrocytes and large amounts of iron.

A diagnosis of virus associated HLH was made on the basis of the typical clinical picture and bone marrow findings. The patient received a transfusion of packed red cells and treatment was started with interferon alfa (2 million units $/ \mathrm{m}^{2}$ by intramuscular injection, daily for one week followed by 3 million units $/ \mathrm{m}^{2}$ three times per week); intravenous immunoglobulin was given $500 \mathrm{mg} / \mathrm{kg}$ daily for three days, and thereafter once weekly for two months. There was a marked clinical improvement over the next two weeks and peripheral full blood counts remained normal.

Two months after beginning treatment with interferon alfa and immunoglobulins, another bone marrow aspirate and trephine was performed. The appearances were identical to those at presentation, but the patient had remained clinically well, with reduction of her hepatosplenomegaly and normalisation of her peripheral full blood counts. Interferon alfa was continued three times per week, with intravenous gammaglobulin every three weeks.

Four months after beginning treatment a third bone marrow aspirate and trephine were performed. The bone marrow aspirate was normal. The trephine biopsy specimen showed active normal haemopoiesis in one complete core. A second core showed similar cellularity with two to three collections of macrophages, which were substantially less iron laden than at diagnosis. The patient completed one year of treatment with interferon alfa and intravenous gammaglobulin, and a third bone marrow aspirate and trephine performed 14 months after her presentation was completely normal. The patient remains in clinical remission 15 months after her presentation with HLH, with normal peripheral blood counts and resolution of her hepatosplenomegaly.

\section{Discussion}

In both cases, the findings of fever, hepatosplenomegaly, and erythrophagocytosis by mature histiocytes were in keeping with a diagnosis of HLH. Sporadic (infection associated) and familial forms of this condition, each of which carries a high mortality, are recognised. Raised triglycerides and low plasma fibrinogen, commoner findings in familial haemophagocytic syndrome were present in case 1 . However, the biochemical abnormalities were mild, the parents non-consanguineous, and her identical twin has been normal to date. Therefore, this patient seemed to have a sporadic, perhaps infection associated haemophagocytic syndrome, rather than the familial form. Case 2 was found to have definite serological evidence of EBV infection, with subsequent development of secondary HLH. Failure to identify herpesvirus infection in case one does not exclude a diagnosis of infection associated HLH. Indeed, in Risdall's original series cases were included on clinical grounds alone. ${ }^{1}$ Subsequently, non-familial haemophagocytic syndromes have been described in association with other viruses, bacteria, opportunistic infections, and $T$ cell lymphoproliferative diseases. This has led to a revision of nomenclature, with the aim of including infection associated and the frequently indistinguishable familial haemophagocytic syndrome within a single group, class $2 \mathrm{HLH}^{2}$

The aetiology of HLH remains unclear and a defect in the immune modulation of histiocytes by $T$ cells has been suggested. In familial $\mathrm{HLH}$, as in other inflammatory conditions, an elevated soluble interleukin-2 receptor level has been found to correlate with disease activity, and this may indicate a proliferation of $\mathrm{T}$ cells or mononuclear cells in an unregulated manner. ${ }^{5}$ Increases in plasma interferon gamma have been have been described in both familial ${ }^{6}$ and infection associated $\mathrm{HLH},{ }^{7}$ and a decrease in natural killer cell function has been found in association with familial $\mathrm{HLH}{ }^{8}$ Although natural killer cell activity was found to be at the low end of the normal range in case one, significant cytotoxicity was present against natural killer cell resistant tumour targets (fig 1). This cytotoxicity, qualitatively similar to lymphocyte mediated lymphokine activated killing (LAK activity), disappeared when adherent cells were removed from the assay. This raises the novel possibility that the apparent spontaneous LAK activity was mediated by activated peripheral blood monocytes or adherent lymphokine activated killer (A-LAK) cells. We do not know if this activity was relevant to the pathogenesis of the $\mathrm{HLH}$ in case one, or if treatment with interferon alfa corrected this finding, but the increase in LAK 
activity had disappeared when the patient was tested when in remission. Natural killer cell activity was found to be within normal limits in case 2 .

High untreated mortality of infection associated HLH has led to the development of nonspecific immunomodulatory therapy with etoposide, corticosteriods, gammaglobulin and, in resistant cases, allogenic bone marrow transplantation. ${ }^{3}$ Infection associated $\mathrm{HLH}$ has also been reported to respond to monotherapy with gammaglobulin ${ }^{9}$ and cyclosporin. ${ }^{10}$

Interferon alfa has direct viral and immunomodulatory effects, with effects on macrophage, cytotoxic $T$ cell and natural killer cell activity. ${ }^{112}$ Interferon alfa has shown clinical activity in the treatment of chronic hepatitis $B^{13}$ and $T$ lymphoblastic disease ${ }^{14}$ in children. As previously discussed, virus associated $\mathrm{HLH}$ may represent a disorder of $T$ cell mediated regulation of histiocyte function, and we felt that the use of interferon alfa was justified in these cases of nonfamilial HLH on the basis of the potential antiviral and immunomodulatory actions of this biological response modifier. In the first case discussed, the patient had failed to respond to acyclovir and gammaglobulin, and was in immediate danger of dying when the acyclovir was replaced with interferon alfa. In the second case, interferon alfa was coadministered with intravenous immunoglobulin at the outset of treatment because of the favourable response seen in case one. The dose of interferon alfa chosen was that reported by Shapiro et al for the treatment of B cell lymphoproliferative disease. ${ }^{15}$

It is not known, however, if the apparent success of interferon alfa in combination with gammaglobulin in case one could be attributed to augmented natural killer cell function, a direct effect on histiocyte proliferation or the treatment of an undetected viral infection. Similarly, for case 2 , interferon alfa in combination with intravenous gammaglobulin may have had a modulating effect on the associated EBV infection, natural killer cell function, or histiocyte proliferation. It could also be argued that the responses seen were not due solely to treatment with interferon alfa, as both patients received other therapies (acyclovir and intravenous gammaglobulin for case 1; intravenous gammaglobulin for case 2). However, infection associated HLH has a high mortality, especially in patients presenting under 2 years of age, ${ }^{3}$ and we consider that the response seen in case 1 when interferon alfa was introduced to have reversed a progressive deterioration.
In summary, interferon alfa appeared to be active in the treatment of these cases of secondary, infection associated HLH and the clinical responses seen were rapid. We are not sure if the responses seen were due to the effect of interferon alone, or to a combination of interferon and gammaglobulin. Although interferon alfa has short term side effects with fever and myalgia, etoposide, more widely used in the treatment of $\mathrm{HLH}$, is a known carcinogen. ${ }^{16}$ Therefore, further evaluation of the use of interferon alfa in the treatment of secondary, infection associated HLH is warranted.

EJE was supported by the North of England Children's Cancer Research Fund and the Leukaemia Research Fund. We would also like to thank Dr MM Reid for critical review of the manuscript.

1 Risdall RJ, McKenna RW, Nesbit ME, Krivit W. Virus associated hemophagocytic syndrome. Cancer 1979;44:9931002 .

2 Reiner AP, Spivak JL. Hemophagocytic histiocytosis : a report of 23 cases and a review of the literature. Medicine report of 23 cases

3 Hirst WJR, Layton DM, Singh S, et al. Haemophagocytic lymphohistiocytosis: experience at two UK centres. $B r \mathcal{F}$ Haematol 1994;88:731-9.

4 Bolme P, Henter J-I, Winiarski J, et al. Allogenic bone marrow transplantation for hemophagocytic lymphohistiocytosis in Sweden. Bone Marrow Transplant 1995;15:331-5.

5 Komp DM, Buckley PJ, McNamara J, Van Hoff J. Soluble interleukin-2 receptor in hemophagocytic lymphohistiocytosis: searching for markers of disease activity. Pediatr Hematol Oncol 1989;6:253-64.

6 Henter JI, Elinder G, Soder O, Hansson M, Andresson B, Andresson U. Hypercytokinaemia in familial hemophagoAndresson U. Hypercytokinaemia in familial hem

7 Imasuku S, Hibi S, Fujiwara F, Ikushima S, Todo S. Haemophagocytic lymphohistiocytosis, interferon-gammanaemia and Epstein-Barr virus involvement. $B r \mathcal{F}$ Haemato 1994;88:656-8

8 Eife R, Janka GE, Belohradsky BH, Holtmann BH. Natural killer cell function and interferon production in familia hemophagocytic lymphohistiocytosis. Pediatr Hematol Oncol 1989;6:265-72.

9 Goulder P, Seward D, Hatton C. Intravenous immunoglobulin in virus associated haemophagocytic syndrome. Arch Dis Child 1990;65:1275-7.

10 Watson HG, Goulden NJ, Manson LM, McDermid G, Gray JA, Parker LC. Virus associated haemophagocytic syndrome: further evidence for a T- cell mediated disorder. syndrome: further evidence for

11 Mengan TC. Human interferon as a therapeutic agent. $N$ Engl F Med 1988;318:145860.

12 Dianzani F. Biological basis for the use of interferon. Gut 1993;34 (2 suppl): S74-6.

13 Narkewicz MR, Smith D, Silverman A, Vierling J, Sokol RJ Clearance of chronic hepatitis B virus infection in young children after alpha interferon treatment. $\mathcal{F}$ Pediatr 1995; 127:815-8.

14 Lauer SJ, Ochs J, Pollock BH, Buchanan GR. Recombinant alpha-2B interferon treatment for childhood $T$ -lymphoblastic disease in relapse. A Pediatric Oncology Group Phase II study. Cancer 1994;74:197-202.

15 Shapiro RS, Chauvinet A, McGuire W, Pearson ADJ, Craft AW, McGave P. Treatment of B cell lymphoproliferative disease with interferon alpha and intravenous gammadisease with interferon alpha and intravenous
globulin. $N$ Engl $₹$ Med 1988;318:1334 (letter).

16 Hawkins MM, Kinnear- Wilson LM, Stovall MA, et al. Epipodophyllotoxins, alkylating agents, andradiation risk of secondary leukaemia after childhhod cancer. $B M \mathcal{F} 1992$ 304:951-8. 